\title{
УДК 303
}

Чан Янь

Хэйлунцзянский государственный университет, Харбин, e-mail: changyan-2000@163.com

\section{B. А. Останин}

Российская таможенная академия, Владивостокский филиал, Владивосток, e-mail: ostaninva@yandex.ru

\section{МЕЖДУНАРОДНАЯ ПОЛИТИЧЕСКАЯ ЭКОНОМИЯ КАК ТЕОРЕТИЧЕСКАЯ БАЗА ПОЗНАНИЯ ПРОЦЕССОВ НА ПОЛИТИЧЕСКИХ РЫНКАХ}

Ключевые слова: международная политическая экономия, политические рынки, экономические и политические противоречия в международных экономических отношениях, формы разрешения международных экономических и политических противоречий.

Статья посвящена углублению понятия новой для российской научной экономической школы научной дисциплины - международная политическая экономия. Рассматриваются объективные и субъективные причины появления научного интереса как российских, так и иностранных ученых к этой относительно новой области научного знания. Рассматриваются проблемы становления, функционирования политических рынков, на которых разрешаются объективные экономические, политические, социальные противоречия между экономическими субъектами. Международная политическая экономия свой предмет исследования переносит на анализ международных экономических рынков в их органической взаимосвязи с политическими рынками. Деятельность субъектов международной экономической политики в данной статье понимается как целенаправленная деятельность суверенных государств, а также международных экономических и политических институтов, которые обладают компетенциями, признанными мировым сообществом. Международная политическая экономия не может абстрагироваться от места политических и экономических агентов, интересы которых могут игнорироваться. Однако при определенных условиях в соответствии с теорией благосостояния акторы экономической политики могут становиться субъектами политических процессов, а, следовательно, оказывать влияние на состояние спроса и предложения на международные политические рынки. При этом возникают свой суверенные, но тем не менее, частные интересы соотносительно с интересами всего международного экономического и политического сообщества суверенных государств.

\section{Zhang Yan}

Heilongjiang State University, Harbin, e-mail: changyan-2000@163.com

\section{A. Ostanin}

Russian Customs Academy, Vladivostok Branch, Vladivostok, e-mail: ostaninva@yandex.ru

\section{INTERNATIONAL POLITICAL ECONOMY AS A THEORETICAL BASIS FOR KNOWING THE PROCESSES IN POLITICAL MARKETS}

Keywords: international political economy, political markets, economic and political contradictions in international economic relations, forms of resolving international economic and political contradictions.

The article is devoted to deepening the concept of a new scientific discipline for the Russian scientific economic school - international political economy. The objective and subjective reasons for the emergence of scientific interest of both Russian and foreign scientists in this relatively new field of scientific knowledge are considered. The problems of the formation, functioning of political markets, which resolve objective economic, political, social contradictions between economic entities. International political economy transfers its subject of research to the analysis of international economic markets from an organic relationship with political markets. The activity of the subjects of international economic policy in this article is understood as the purposeful activity of sovereign states, as well as international economic and political institutions that have competencies recognized by the world community. International political economy cannot abstract from the place of political and economic agents, whose interests can be ignored. However, under certain conditions, in accordance with the theory of welfare, the actors of economic policy can become subjects of political processes, and, consequently, influence the state of supply and demand on international political markets. This gives rise to its own sovereign, but nevertheless, private interests in relation to the interests of the entire international economic and political community of sovereign states. 


\begin{abstract}
Введение
Объектом изучения международной политической экономии являются международные экономические отношения, находящиеся во взаимосвязи с отношениями, которые складываются по этому поводу на политических рынках. И если экономические отношения раскрывают сущность противоречивых взаимосвязей на международных экономических рынках, то политические отношения отражают скорее процессы оформления последних в воле институтов, опираясь при этом на внеэкономическое понуждение и вменение своих устремлений, вожделений в итоговые процессы распределения богатства и его присвоения. Международная политическая экономия, изучая международные экономические рынки, внимает в свой мегаэкономический анализ состояние и процессы, происходящие на политических рынках. Более того, политические рынки становятся регуляторами различных сфер экономики и политики, не выбрасывая за границы своего предмета проблемы национального суверенитета и национальной безопасности. В данной статье под экономической политикой понимается целенаправленная деятельность субъектов, включая правительства суверенных государств, международных экономических, политических институтов, обладающих компетенциями по разработке и принятию стратегических решений и воплощении их в действительность как внутри самих политических институтов, так и вненациональных сферах.
\end{abstract}

\section{Состояние научной проблемы}

Как отмечает А.А. Афонцев, формирование международного политического рынка в теории международной политической экономии должно рассматриваться в русле нормативного анализа экономической политики через призму теории благосостояния, игнорируя при этом интересы политических агентов. Однако слабость данного подхода усматривается в том, что акторы теории благосостояния сами могут становиться субъектами политических процессов, у которых неизбежно появляются свои, обособленные от общих, частные интересы. Это положение вытекает из взаимоотношений и интерпретаций «субъективных» и «объективных» интересов [1].

На политических рынках по аналогии с рынками благ также мы можем обнару- жить акторов, формирующих спрос на политические решения, политические институции, в том числе в сфере международных экономических отношениях, которые призваны удовлетворять те или иные слои в национальных государствах.

\section{Метод исследования}

Со стороны предложения выступают субъекты политических новаций, эти субъекты наделены властными полномочиями в законотворчестве. Как отмечают некоторые авторы, это политический рынок также может находиться в состоянии как эффективного, так и неэффективного равновесия. Посложнее качество позволяет трактовать это состояние как «ловушку политического института» [2]. Наделенные властью и компетенциями, которые даны потенциалом международного частного права, например, эти политики могут не выражать, игнорировать требований политического рынка, преследуя тем самым свой частные интересы. В результате экономическая политика, воплощаясь посредством правоустанавливающих документов, по своей сути становится частной межгосударственной политикой [3]. Это придает особую специфику в понимании теоретической базы такой научной дисциплины, как международная политическая экономия.

И хотя сама научная дисциплина Международная политическая экономия является относительно новой для российской действительности, тем не менее определенные достижения были сделаны. Здесь достаточно подчеркнуть вклад таких ученых, как С.А. Афонцев [1;4;5], Г.А. Дробот [6].

Из иностранных ученых следует отметить важный вклад в развитие предмета теории Международной политической экономии таких ученых, как: Bhagwait J. [7], Cline W. [8], Cooper R. [9], Dixit A., Norman V. [10] и др.

Так, в работе Bhagwait J. (1991) [7] была рассмотрена проблема системных рисков, которые генерируются в мировой торговле. Актуальность выводов, которые были получены конце XX столетия весьма наглядно проявились в настоящее время в период введения санкций. Однако санкции, которые накладываются в мировой торговле на другие государства, есть объект исследования уже иной сферы, а именно, политических рынков и их состояния. Это обстоятельство 
объективно порождало уже не отдельные, a системные риски. Cline W., анализирует суть и последствия реализуемой США торговой политики в восьмидесятые годы [8].

Наиболее в категоричной форме связь между торговой политикой и внешней политикой государств на примере взаимосвязи торговых преференций и ограничений, а также деятельностью государства, когда последнее реализует свою внешнюю политику можно обнаружить в статье Coоper, Richard N. «Trade Policy Is Foreign Policy» [9].

Если речь вести уже о взглядах, которые получили своё системное выражение, то в данном отношении наибольший интерес представляет труд Dixit A., и Norman V. «Theory of International Trade». Теория торговли в работе объясняет торговое равновесие, которое является общим, а не частичным равновесием. И государство, реализуя свою торговую политику, может допускать некоторые ошибки и недоразумения. И хотя авторы в работе не говорят о политических рынках, тем не менее из контекста эта взаимосвязь просматривается вполне однозначно [10].

Однако раскрыть причинную связь той или иной торговой политики и состояния политических рынков можно только тогда, когда сами политические рынки станут рассматриваться в единстве с торговой, миграционной, инвестиционной, валютнокредитной политикой. Но в этом случае необходимо в сам предмет исследования вводить уже не столько акторов, сколько субъектов политических отношений, не впадая при этом в политологию. В исследованиях, которые посвящены состоянию рынка, необходимо включать в предмет сам процесс распределения власти, используя при этом как легитимные, так и нелегитимные с позиций международного торгового, финансового, таможенного и иного вида права, что составляет объект международной политической экономии.

В результате можно обнаружить за каждым процессом, политическим решением следы как соперничества, так и согласования интересов экономических и политических субъектов. Торг, экономические сделки, прикрытые политическими сделками есть естественная среда существования предмета международной политической экономии. Инструментами в реализации и воплощении экономической, налоговой, таможенной, миграционной и т.д. политики являются как экономические, политические институции, а также инструменты «грубой силы, например, применение или угроза применения вооружённых сил или нелегальных вооруженных формирований. В конечном счете, результат подобного соперничества может лежать в применении грубой силы в контроле над территориями, мировыми грузопотоками.

\section{Анализ инструментов исследования научной проблемы}

Особенность современного состояния развития международных экономических, политических отношений видится в том, что уже начиная с 70-х годов в мегоэкономический анализ следует вводить влияние фактора экономической силы, мощь экономического потенциала - мировые запасы энергоресурсов, находящихся на территориях национальных государств, и их доступность для остального мира. Начало 21 века привнесло в мегаэкономический анализ дополнительно учет фактора политических новаций, которые ранее не принимались во внимание, по крайней мере, им не придавалось такого значения, например, политика экономических санкций на результаты политических решений других стран. Достаточным для доказательства примером может стать наложение санкций на Россию в результате воссоединения Крыма с Россией на основе народного референдума в 2014 году.

Так, ближневосточные страны, входящие в ОПЕК, открыто впервые в 1973 году использовали потенциал «нефтяного оружия» в отношении стран западной коалиции. Следующим примером можно привести позицию Ирана, который противостоит странам Запада, настаивающих на сворачивании ядерной программы.

В этом отношении можно утверждать, что формируется формальный и неформальный центры в архитектонике международных отношений, однако следует принимать в качестве очевидного положения, что эти центры реализуют политические и экономические интересы Запада, в частности, Группа семи (G7).

Особенностью этой международной организации является то, что она не скреплена каким-то международным договором, 
не имеет устава, официально закрепленного органа управления в форме секретариата. И хотя её решения не обладают обязательной для всех участников силой, тем не менее страны, входящие в эту неформальную структуру, проводят скоординированную политику как по отношению к собственным членам G7, так и по отношению к остальным членам мирового экономического сообщества.

Дополнительными факторами, которые формируют новое качество международных экономических и политических отношений и одновременно модифицируя объект и сам предмет научной дисциплины «Международная политическая экономия», - это выход на мировую экономическую и политическую арену новых государств. И если ранее эти государства можно было отнести к государствам акторам, то в последнее время они всё в большей мере занимают нишу государств субъектов. Последние, т.е. государства субъекты мировой политики отличаются от государств акторов по тому признаку, что государства субъекты стали обладать необходимым экономическим, политическим, военным потенциалом, а также руководство этих государств обладает политической волей и могут её реализовать в системе властных отношений соперничества и противоборства интересов.

Произошла деформация в постановке приоритетных целей государств на международной арене, что прежде не проявлялось так выпукло. Обострилась экономическое, политическое, идеологическое и военное противостояние между государствами за более выгодное вложение капитала, приобретению доминирования над мировыми грузопотоками и мировым транспортными артериями, которое способны обеспечивать в том числе и энергетическую безопасность стран. В результате можно наблюдать подрыв в некоторых странах качеств национальной безопасности, потере национального суверенитета, а также стран-должников, которые уже не могут в обозримом будущем погасить свои долги перед таким странамикредиторами, и мировыми финансово-кредитными институтами.

Специфика современных международных отношений и одновременно теоретической проблемой международной политической экономии является то, то предметом международных сделок становятся территории. Последние представляют уже не столько как жизненное пространство, а как возможность доступа к природным ресурсам и их эксплуатации, игнорируя при этом жизненные интересы народов, которые проживают на этих территориях. Речь идет и потере суверенитета над этими территориями. В результате подобных экономических и политических сделок на политических и экономических рынках страны теряют свою суверенность, т.е. утрачивают, либо существенно ограничивают свой государственный суверенитет.

Если прежде эти противоречия разрешались в результате применения вооруженных сил, вооруженных конфликтов, что позволяло словами Бисмарка говорить о «кошмаре коалиций», то современная специфика формирования международных политических отношений начинает предопределяться формированием глобального экономического и политического пространства. Процесс глобализации перегруппирует все экономическое сообщество, выделяя крупные мировые центры экономического и политического влияния.

Проблема международной политической экономии в сделках, объектом которых становятся права на использование, присвоение (отчуждение) территорий, является цена, а именно, что лежит в основе этой цены? Другими словами, на основе каких пропорций происходит обмен, передача прав?

Представляется, что в основе этих пропорций сделок на экономических рынках лежит мощь экономических субъектов. Последняя раскрывается в мощи экономической, мощи политической, военной, наконец, в потенциале «мягкой силы», которыми обладает каждый субъект международных сделок. И чем относительно меньше качественных и количественных факторов, которые определяют пропорции обмена, тем больше вероятность того, что более слабая сторона будет полагать себя в качестве стороны, чьи интересы были несправедливо по её оценкам нарушены.

Данную тенденцию мы можем легко обнаружить в истории мировой экономики. Как отмечает Г.А. Дробот, например, «Англия явилась инициатором принципиально новой «нетерриториальной международной политики» (Р. Роузкранц). До этого если какое-то государство становилось сильнее других, оно стремилось к военно-терри- 
ториальному преимуществу. Англия видела свою выгоду в другом -экономической специализации и торговле. До 1840-х гг. ничего подобного в международных отношениях не было. Однако усиление роли экономической составляющей мировой политики было в XIX веке лишь эпизодом, а не тенденцией. Конец системы свободной торговли обозначился в последние годы века, но окончательно она рухнула с началом Первой мировой войны. После нее и вплоть до конияа Второй мировой войны в мире доминировала военнополитическая система координат» (Bыделено нами - Ч.Я, В.О.) [6].

Соглашаясь с выводами Г.А. Дробот в первой части цитируемого нами тезиса, нельзя не отметить и того факта, который легко обнаруживается в настоящее время. Военно-политическая система координат продолжает доминировать.

При этом в международном политэкономическом анализе не следует исключать и такой деформирующий мировые рынки фактор, как например, харизма первых руководителей государств, которые способны оказывать доминирующее влияние на мировые рынки. Материальная выгода, которая выступает стимулом в рыночных экономиках в микроэкономическом анализе, уже не выступает в качестве доминирующего фактора тогда, когда речь идет о переделе мира вообще. Страх и голод, перспектива лишения материальных ценностей не всегда доминировали в выборе мотивов поведения национальной элиты. Даже в настоящее время предприниматели ориентированы на получение дохода. Однако их роль уже не становится столь существенной. Чтобы убедиться в этом положении, достаточно проанализировать отношение руководства Китая и крупному бизнесу. Полагаем, что в Китае в процессе построения социализма с китайской спецификой бизнес продолжает оставаться скорее островками в океане доминирования общенациональных интересов. В результате можно сделать вывод о том, что что мотив прибыли, мотив денег, ориентация исключительно на доход, стремление к наживе следует рассматривать не более как момент в длительной истории развития человеческой цивилизации» [11].

Это положение дает основание рассматривать как объект, так и предмет научной дисциплины «Международная политиче- ская экономия» не с позиции sub specie aeternitatis, а позиции sub specie temporis. Дополнительно здесь следует принимать во внимание то фундаментальное положение, что целеполагание доминирующих на мировых товарных рынках государства, обладающие мощным политическим весом, мощными вооруженными силами, развитыми информационными технологиями формируют общую детерминанту развития человеческой цивилизации, предопределяют вектор и ориентиры экономического, политического, информационного развития общества, оставаясь одновременно формой выражения уже более сущностного и вневременного, т.е. субстанционального [11].

Этой сущностью в раскрытие природы современных международных отношений становится воля доминирующих на мировых рынках государств. Международная политическая экономия уже не может абстрагироваться от этих феноменов. Работы последних лет позволяют трактовать волю доминирующих государств как социальное явление, базирующее на глубоких онтологических основаниях. Воля руководства таких государств как Китай, США способны переформатировать всю рыночную, а одновременно и политическую архитектонику. Здесь уже воля приобретает модифицированные формы как воля к власти.

Эта мировая воля модифицирует себя как «воля к власти», понимаемая одновременно как «воля к жизни», реализуемая о достигаемая своих целей раньше у тех, кто в большей мере обладает этой мощью, раскрывающейся как объективном состоянии производительных сил, так и в субъективном потенциале руководителей государств. Таким образом мировая воля уже не предстает как «темное начало» у Артура Шопенгауэра. Более того, она есть источник всего сущего, в том числе познания природы и потенциала такой научной дисциплины, как Международная политическая экономия.

Следовательно, сложно, если только невозможно, понять суть процессов, которые мы можем обнаружить на товарных и политических рынках. Мировая воля без привлечения инструментария разума будет всегда оставаться своего рода кантовской «вещьв-себе». Происходящие на товарных и политических рынках скорее будут являться нам не более как представления, лишенные в содержании смысла. 
Глобальные игроки, которые доминируют на современных товарных и политических рынках, формируют сам объект изучения международной политической экономии. Этот мир, как например, формирование Сообщества единой судьбы человечества», построение модели социализма с китайской спецификой, затрагивает уже практически все человечество. Однако, как нам представляется, это скорее еще есть модель творения «темных» сил общественной природы, если остальной мир, который волей-неволей сопряжен с реализацией таких глобальных проектов, как «Один пояс - Один путь» не до конца осознает, как плюсы, так и минусы этих проектов. Здесь важно отметить то, что мировая воля, как «темное начало» начинает доминировать в принятии решений на экономических и политических рынках. Однако будучи познанной разумом мировая воля доминирующих государств будучи познанной уже переходит в своё отрицание, превращаясь в разумную экономическую, военную, таможенную, демографическую инвестиционную и иную политику. Власть международных экономических, политических, военных отношениях есть проявление воли в мировой торговли, сознании институтов воспроизводства угроз применения насилия. Эти процессы формируют механизмы подчинения, подавления воли других членов мирового сообщества, а, следовательно, создают более выгодные условия реализации процессов присвоения, распоряжения, потребления продуктов, присвоенных в результате несправедливого, неэквивалентного обмена. Следовательно, мировая воля, власть в международных экономических отношениях впаяна в отношения собственности, в результате собственность может быть отражена более адекватно как некоторая целостность, или тотальность. Тем самым отношения присвоения, распоряжения богатством внутри мирового сообщества становится материальной основой для других ветвей власти, например, политической.

В результате диалектика отношений экономики и политики уже не становятся такими простыми, как это следует из работ классиков. Экономика может быть представлена как некоторый базис, но одновре- менно, по теории В.И. Ленина, политика не может не иметь первенства над экономикой. Здесь мы получили два контрадикторных суждения, в истинности обеих есть основания сомневаться. Причина нам видится в ошибке методологического подхода к рассмотрению проблемы с позиций механического детерминизма. Принцип целостности в познании, которому авторы следуют в данной статье, позволяет перейти от упрощенного понимания данной проблемы взаимоотношений к диалектическому детерминизму. Здесь каждое суждение отражает лишь момент истины, эти суждения отражают процесс диалектического проникновения каждой стороны в свою противоположность. Потому механический детерминизм здесь неуместен. Эти объективные, или предметные, по Ф.Ф. Вяккереву, противоречия, также должны стать объектом изучения научной дисциплины Международная политическая экономия.

Воплощая в практику политику построения общества среднего достатка, Китай, например, вынужден притягивать в промышленный оборот ресурсы, которые уже для самого Китая становятся недостаточными. Эти ресурсы воплощены в объектах природы творящей и производящей (natura natarans), а также природы творимой или производимой (natura natarata). И если первые можно отнести к «даровым силам» природы, то вторые доступны уже в силу самой научно-производственной деятельности человека. Но когда достижение, достигнутые предшествующими поколениями, начинают трансформироваться из ресурсов в факторы воспроизводства, то они для последующих поколений также становятся (natura natarans), что делает из по сути теми же «даровыми салами» но уже общественного развития и научнотехнического прогресса.

Из этого становится понятным тот накал соперничества между передовыми в техническом и научном отношении стран. Следовательно, международная политическая экономия должна ввести свой объект изучения состояние процесса присвоения достижений науки, техники и технологий, а также формирование и усвоения институтов развития на международных товарных и политических рынках. 
Библиографический список

1. Афонцев С.А. Политические рынки и экономическая политика. 2-е изд. М.: ЛЕНАРД, 2015. 352 с.

2. Останин В.А. Экспансионистская политика Китая на газовых рынках Центральной Азии: политологический аспект // Финансовая экономика. 2020. № 9.

3. Останин В.А. Общая и частная экономическая политика государства: проблемы взаимоотношения и взаимообусловленности // Таможенная политика России на Дальнем Востоке. 2013. № 4(65).

4. Афонцев С.А. Проблема глобального управления мирохозяйственной системой: теоретические аспекты // Мировая экономика и международные отношения. 2001. №5.

5. Афонцев С.А. Экономическая политика в современном мире: «глобальное управление» или глобальный политический рынок // Мировая политика и международные отношения на пороге третьего тысячелетия / под ред. М.М. Лебедевой. М., 2000.

6. Дробот Г.А. Особенности взаимосвязи политики и экономики в глобализирующихся международных отношениях (политологический анализ): дис. ... д-ра полит наук: 23.00.04. М.: МГУ, 2006. 212 с.

7. Bhagwait J. The World Trade System at Risk. Princeton, 1991. 452 p.

8. Cline W. Trade Policy in 1980s. Washington, 1983. 385 p.

9. Cooper R. Trade Policy Is Foreign Policy // Foreign Policy. № 9 (Winter 1972-1973). P 845-854.

10. Dixit A., Norman V. Theory of International Trade. New York, 1980. 564 p.

11. Останин В.А. Философия присвоения: монография. Владивосток: Изд-во ВФ РТА, 2012. 368 с. 